\title{
Renal Oxygen Consumption and Sodium Reabsorption during Isotonic Volume Expansion in the Developing Rat
}

\author{
GÖRAN ELINDER ${ }^{(24)}$ AND ANITA APERIA \\ Department of Paediatrics, Karolinska Institute, St. Göran's Children's Hospital, Box 12500, \\ S-11281 Stockholm, Sweden
}

\begin{abstract}
Summary
The aim of the present study was to obtain more information on oxygen consumption in relation to $\mathrm{Na}$ reabsorption in the immature kidney during hydropenia (HP) and isotonic volume expansion (VE) corresponding to $5 \%$ of the body weight. The study was performed in 24 male Sprague Dawley rats, which were divided into four groups containing six rats each: (1) 22- to 24-day-old rats during HP; (2) 22- to 24-day-old rats during VE; (3) 40- to 42-dayold rats during HP; and (4) 40- to 42-day-old rats during VE. Blood from the renal vein and from the artery was sampled for estimation of oxygen consumption. Glomerular filtration rate (GFR) was estimated by inulin clearance and renal plasma flow by renal extraction of inulin.

Hemoglobin conentration and hematocrit are lower in younger rats than in older ones. VE induces a significant and equivalent fall in both age groups. During HP, renal blood flow (RBF) and GFR in relation to body weight are almost $50 \%$ lower in younger than in older rats $(P<0.001)$. During VE, RBF and GFR increase by almost $100 \%$ in younger rats $(P<0.001)$ and reach the same values as in older rats $(P>0.05)$. The RBF and GFR increased by about $15 \%$ in the older rats during the transition from $\mathrm{HP}$ and VE $(P>0.05)$. The amount of $\mathrm{Na}$ reabsorbed in 24-day-old HP rats was only $56 \%$ of the amount of $\mathrm{Na}$ reabsorbed in 40-day-old rats $(P<0.001)$. After VE, Na reabsorption increased more in 24 than in 40-day-old rats (by $52 \%$ and $12 \%$, respectively). The fractional sodium excretion $\left(\mathrm{C}_{\mathrm{Na}} / \mathrm{C}_{\text {in }}\right)$ was lower in the 24 - than in the 40-day-old VE rats. Renal oxygen consumption (ROC) in the 24-day-old HP rats (including basal oxygen consumption of 1 $\mu$ mole/g kidney weight) was $53 \%$ of the ROC in 40 -day-old HP rats. During VE, ROC increased more in the 24 -day-old rats (34\% )$(P<0.01)$ than in the 40-day-old rats $(4 \%)(P>0.05)$.
\end{abstract}

The renal $\mathrm{Na} / \mathrm{O}_{2}$ ratio was the same in the 24-day-old $\mathrm{HP}$, the 40-day-old HP and the 40-day-old VE rats. The 24-day-old VE rats had a significantly higher $\mathrm{Na} / \mathrm{O}_{2}$ ratio than the other groups studied $(P<0.01)$.

It is concluded that the energy demands of the immature kidney are related to the GFR and the amount of reabsorbed $\mathrm{Na}$. If the GFR and the amount of reabsorbed $\mathrm{Na}$ increase, the oxygen consumption also increases. The amount of the increase, however, is less in the younger rats during VE than it would be if the renal $\mathrm{Na} / \mathrm{O}_{2}$ ratio was fixed.

\section{Speculation}

Equivalent volume expansion induces a considerably larger increase in glomerular filtration rate and a concurrent increase in $\mathrm{Na}$ reabsorption in the neonatal period. Because the increased $\mathrm{Na}$ reabsorption during $\mathrm{VE}$ is partly due to increased $\mathrm{O}_{2}$-demanding Na transport, VE may be hazardous, at least in the neonatal period when the oxygen and energy resources are limited.
Under basal conditions the immature kidney is able to conserve water and electrolytes by means of a low renal blood flow (RBF) and a low glomerular filtration rate (GFR) $(4,11,12,15)$. The resulting small filtered load should lower the need for energydemanding tubular reabsorption.

In the mature kidney, renal oxygen consumption (ROC) depends mainly on the amount of reabsorbed sodium $(5,9)$, which in turn is largely determined by the amount of filtered $\mathrm{Na}$. In the adult animal, ROC during hydropenia (HP) corresponds to 8-10\% of the total body oxygen consumption (16). Volume expansion (VE) amounting to $10 \%$ of the body weight (bw) increases the amount of filtered and reabsorbed $\mathrm{Na}$ and also increases $\mathrm{ROC}$ to about $15 \%$ of the total body oxygen consumption (22).

The aim of the present study was to obtain more information on oxygen consumption in relation to $\mathrm{Na}$ reabsorption in the immature kidney during HP and VE. Earlier studies from this laboratory have shown that during moderate VE, the immature kidney responds with a much more prompt increase in RBF, GFR and $\mathrm{Na}$ reabsorption than does the mature kidney (12). If the increased $\mathrm{Na}$ reabsorption during $\mathrm{VE}$ is due mainly to increased $\mathrm{O}_{2}$-demanding active $\mathrm{Na}$ transport, $\mathrm{VE}$ could increase the oxygen consumption considerably. This could have clinical implications, at least in the neonatal period when the oxygen resources are limited.

\section{MATERIALS AND METHODS}

The studies were performed on 24 male Sprague Dawley rats. The bw of the younger and the older rats averaged $66.2 \pm 2.6 \mathrm{~g}$ (mean \pm S.D.) and $151.2 \pm 18.1 \mathrm{~g}$ (mean \pm S.D.), respectively. The rats were weaned up to 17 days of age. Before the study, all animals were given water ad libitum and an ordinary laboratory diet. The rats were divided into four groups containing six rats each: (1) 22- to 24-day-old rats during HP (24-d HP); (2) 22- to 24-day-old rats during VE (24-d VE); (3) 40- to 42-day-old rats during HP (40-d HP); and (4) 40- to 42-day-old rats during VE (40-d VE).

Preparations. The rats were anesthetized with $80 \mathrm{mg} / \mathrm{kg}$ Inactin (Promonta, West Germany) intraperitoneally and intubated with a polyethylene catheter (pp-205). The rats were kept warm with an infrared lamp. The rectal temperature ranged between $37^{\circ}-$ $37.5^{\circ} \mathrm{C}$. Cannulae were placed in one or both jugular veins and one carotid artery. The left renal vein and ureter were approached by means of a subcostal incision in the left flank. Urine was obtained from a cannula positioned in the ureter $8-10 \mathrm{~mm}$ distal to the pelvis. The renal vein was cannulated by a sharp needle $(0.3 \mathrm{~mm})$ anaerobically connected to a $1 \mathrm{ml}$ heparinized syringe (Braunswick). The piston was exposed to a continuous mechanical traction, which resulted in suction of $0.5 \mathrm{ml}$ renal vein blood into the syringe at a rate of $0.3 \mathrm{ml} / \mathrm{min}$ in younger rats and $0.6 \mathrm{ml} / \mathrm{min}$ in older rats. The position of the needle was at least $5 \mathrm{~mm}$ from 
the renal vein's entrance into the inferior vena cava. Arterial blood was sampled from the carotid artery. A continuous infusion of inulin $(6.25 \%)$ in Ringer's solution was given at a rate of 0.015 $\mathrm{ml} / 100 \mathrm{~g} \mathrm{bw} / \mathrm{min}$. The infusion was started $1 \mathrm{~h}$ before the study and was preceded by a prime dose of $1 \mathrm{ml} / 100 \mathrm{~g}$ bw of the same solution. The fluid used for expansion in group 24-d VE and group 40-d VE consisted of isotonic sodium chloride given in the other jugular vein $30 \mathrm{~min}$ before sampling. The infusion rate was $0.25 \mathrm{ml} / 100 \mathrm{~g} \mathrm{bw} / \mathrm{min}$ the first $20 \mathrm{~min}$ and $0.07 \mathrm{ml} / 100 \mathrm{~g} \mathrm{bw} / \mathrm{min}$ during the rest of the study. Urinary sampling was started 70-80 min after the prime dose of inulin and terminated 20-30 min later. The blood samples were immediately sealed and put into ice water. The arterial blood pressure was determined periodically by connecting the carotid artery catheter to a Hewlett-Packard pressure recorder (No. 7744A).

Analytical procedures. The concentrations of hemoglobin $(\mathrm{Hb})$, $\mathrm{pH}$ and $\mathrm{PO}_{2}$ in $0.1 \mathrm{ml}$ of either arterial or venous blood were recorded in a blood-gas analyzer (ABL 2, Radiometer, Copenhagen). The oxygen saturation was calculated from an oxygensaturation curve estimated earlier from Sprague Dawley rats, to $\mathrm{pH}=7.35-7.45$ (11).

The accuracy of the $\mathrm{Hb}$ measurements, using $\mathrm{ABL} 2$, was checked in 20 double samples by means of conventional cyanmeth-hemoglobin methods used routinely in our laboratory. No significant difference was found between the methods.

Calculations. In the left experimental kidney, GFR was estimated with inulin clearance, renal plasma flow (RPF) by renal extraction of inulin according to the formula: $R P F=\dot{V}\left(U_{i n}-\right.$ $\left.V_{\text {in }}\right) /\left(A_{\text {in }}-V_{\text {in }}\right) . \dot{V}$ is the rate of urinary flow, $U_{\text {in }}, V_{\text {in }}$ and $A_{\text {in }}$ are the concentration of inulin in urine, renal vein plasma and artery plasma, respectively. Oxygen consumption was estimated by multiplying RBF (RPF/1-Hct) by the arteriovenous difference of the blood oxygen content.

Basal oxygen consumption was calculated from the regression line, when the sodium reabsorption was zero. This value was found to be $0.5 \mu \mathrm{mole} / \mathrm{min} / 100 \mathrm{~g} \mathrm{bw}$, a value in accordance with earlier findings of $1 \mu \mathrm{mole} / \mathrm{g}$ kidney weight $/ \min (5,16)$. The $\mathrm{Na} /$ $\mathrm{O}_{2}$ ratio was calculated by dividing the amount of $\mathrm{Na}$ reabsorbed

Table 1. Hemoglobin, hematocrit and serum- $\mathrm{Na}$ in 24. and 40. day-old hydropenic (HP) and volume-expanded (VE) rats $^{1}$

\begin{tabular}{llll}
\hline $\begin{array}{c}\text { Age and state } \\
\text { of hydration }\end{array}$ & $\begin{array}{l}\text { Hemoglobin con- } \\
\text { centration }(\mathrm{g} / \mathrm{ml})\end{array}$ & \multicolumn{1}{c}{ Hematocrit } & $\begin{array}{c}\text { Serum } \mathrm{Na}^{+} \\
(\mu \mathrm{mole} / \mathrm{ml})\end{array}$ \\
\hline 24-day HP & $0.116 \pm 0.090^{3.4}$ & $0.35 \pm 0.04^{3,4}$ & $144.0 \pm 4.1$ \\
24-day VE & $0.097 \pm 0.010^{2.4 .5}$ & $0.30 \pm 0.03^{2,4.5}$ & $144.0 \pm 4.0$ \\
40-day HP & $0.144 \pm 0.014^{2,3.5}$ & $0.42 \pm 0.04^{2.3 .5}$ & $148.0 \pm 1.6$ \\
40-day VE & $0.122 \pm 0.023^{3.4}$ & $0.36 \pm 0.06^{3.4}$ & $147.7 \pm 2.8$ \\
\hline
\end{tabular}

${ }^{1}$ Values are mean \pm 1 S.D.

${ }^{2}$ Significantly different from 24-day HP.

${ }^{3}$ Significantly different from 24 -day VE.

${ }^{4}$ Significantly different from 40-day HP.

${ }^{5}$ Significantly different from 40-day VE.
$\left[\left(\mathrm{GFR} \times\right.\right.$ serum $\left.\mathrm{Na}^{+}\right)-\left(\mathrm{C}_{\mathrm{Na}} \times\right.$ serum $\left.\left.\mathrm{Na}^{+}\right)\right]$by the amount of oxygen consumed (actual mean value for oxygen consumption subtracted from the basal oxygen consumption).

Statistical analysis. The sources of variations were analyzed by analyses of variance. The distribution table for $F$ used in the study was $P=0.975$.

\section{RESULTS}

The hemoglobin and hematocrit are lower in younger than in older rats. VE induces a significant and equivalent fall in both age groups. The values for serum $\mathrm{Na}$ are constant in all four groups (Table 1).

During HP, RBF and GFR in relation to body weight are almost $50 \%$ lower in younger than in older rats (Table 2). During VE, RBF and GFR increased by almost $100 \%$ in younger rats and reached the same values as those recorded in older VE rats. The older rats increased their RBF and GFR by about $15 \%$ during the transition from HP to VE.

The reliability of the extraction technique $(21,22)$ for determination of $R B F$ is shown in Table 3 . The values obtained with the extraction technique have been compared with those obtained previously with the microsphere technique (12) under similar experimental conditions. There is a good correlation between the values obtained with the microsphere technique and the values obtained with the extraction technique, although the extraction technique gives $10-15 \%$ higher values than the microsphere technique.

The amount of Na reabsorbed in 24-d HP rats was only $56 \%$ of the amount of $\mathrm{Na}$ reabosrbed in 40-d HP rats. After VE, Na reabsorption increased more in 24- than in 40-d rats (by $52 \%$ and $12 \%$, respectively). Fractional excretion of $\mathrm{Na}$ was lower in 24than in 40-d VE rats. ROC in 24-d HP rats (including basal oxygen consumption of $1 \mu$ mole/g kidney weight) was $53 \%$ of ROC in 40-d HP rats. During VE, ROC increased more in 24-d rats $(34 \%)$ than in $40-d$ rats $(4 \%)$ (Table 2 ).

The renal $\mathrm{Na} / \mathrm{O}_{2}$ ratio was the same in 24-d HP, 40-d HP and 40-d VE rats. The 24-d VE rats had a significantly higher $\mathrm{Na} / \mathrm{O}_{2}$ ratio than the other groups studied.

\section{DISCUSSION}

The measurement of renal oxygen consumption entails certain methodological problems. The value is dependent on eight different primary values, and analytical as well as measurement errors may invalidate the results. The methods used to minimize errors in hemoglobin determinations are discussed in the section "Materials and Methods." The extraction method for RBF determination appears to be as reliable as the microsphere method (12), when comparing RBF in different groups of rats (Table 3 ). The recent criticism of the microspheres method (6) is valid only for measuring regional $\mathrm{RBF}$, not for whole kidney $\mathrm{RBF}$. The $\mathrm{PO}_{2}$ and pH may vary considerably if the samples are not cooled immediately and sealed properly. The low deviation of the mean values

Table 2. Renal blood flow, glomerular filtration rate, fractional sodium excretion, $\mathrm{O}_{2}$-consumption and $\mathrm{Na} / \mathrm{O}_{2}$ ratio in both age groups during hydropenia and isotonic volume expansion ${ }^{1}$

\begin{tabular}{|c|c|c|c|c|c|}
\hline $\begin{array}{l}\text { Age and state of } \\
\text { hydration }\end{array}$ & $\begin{array}{c}\text { RBF } \\
(\mathrm{ml} / \mathrm{min} / 100 \mathrm{~g} \mathrm{bw})\end{array}$ & $\begin{array}{c}\text { GFR } \\
(\mathrm{ml} / \mathrm{min} / 100 \mathrm{~g} \mathrm{bw})\end{array}$ & $\mathrm{C}_{\mathrm{Na}} / \mathrm{C}_{\mathrm{In}}$ & $\begin{array}{c}\mathrm{O}_{2} \text { consumption } \\
(\mu \mathrm{mole} / \mathrm{min} / 100 \mathrm{~g} \\
\mathrm{bw})\end{array}$ & $\begin{array}{c}\mathrm{Na} / \mathrm{O}_{2} \text { ratio } \\
\mu \mathrm{mole} / \mu \text { mole }\end{array}$ \\
\hline 24-day HP & $1.33 \pm 0.94^{3.4 .5}$ & $0.27 \pm 0.10^{3,4,5}$ & $0.009 \pm 0.004^{5}$ & $3.21 \pm 0.94^{3.4 .5}$ & $14.5 \pm 1.7^{3}$ \\
\hline 24-day VE & $2.65 \pm 0.69^{2}$ & $0.52 \pm 0.15^{2}$ & $0.011 \pm 0.005^{5}$ & $4.31 \pm 0.84^{2}$ & $19.6 \pm 3.1^{2,4,5}$ \\
\hline 40-day HP & $2.50 \pm 0.60^{2}$ & $0.47 \pm 0.11^{2}$ & $0.012 \pm 0.008^{5}$ & $4.90 \pm 0.90^{2}$ & $15.3 \pm 2.3^{3}$ \\
\hline 40-day VE & $2.80 \pm 0.71^{2}$ & $0.54 \pm 0.17^{2}$ & $0.027 \pm 0.012^{2}$ & $5.11 \pm 0.81^{2}$ & $16.7 \pm 1.5^{3}$ \\
\hline
\end{tabular}

\footnotetext{
'Values are mean \pm 1 S.D.

${ }^{2}$ Significantly different from 24-day HP.

${ }^{3}$ Significantly different from 24-day VE.

${ }^{4}$ Significantly different from 40-day HP.

${ }^{5}$ Significantly different from 40-day VE.
} 
Table 3. Renal blood flow measured with microspheres and with inulin extraction ${ }^{1}$

Renal blood flow (ml/min)

\begin{tabular}{ccc} 
& Microspheres & Inulin extraction \\
\hline 24-day HP & $0.72 \pm 0.22$ & $0.88 \pm 0.62$ \\
& $(n=6)$ & $(n=6)$ \\
24-day VE & $1.30 \pm 0.03$ & $1.47 \pm 0.46$ \\
& $(n=8)$ & $(n=6)$ \\
40-day HP & $3.42 \pm 0.83$ & $3.77 \pm 0.71$ \\
& $(n=6)$ & $(n=6)$ \\
40-day VE & $3.95 \pm 0.87$ & $4.22 \pm 1.07$ \\
& $(n=7)$ & $(n=6)$ \\
\hline
\end{tabular}

${ }^{1}$ Mean values \pm 1 S.D. with number of rats per group in parentheses.

and the close resemblance of the oxygen consumption values earlier reported in rats speak against systematic as well as analytical errors (21).

During hydropenia, the renal $\mathrm{Na} / \mathrm{O}_{2}$ ratio was approximately the same in 24- and 40-d rats. This could imply that the energy demand for $\mathrm{Na}$ transport is similar in the immature and mature kidney. It should, however, be pointed out that the present study was performed on a whole kidney preparation and that there is a maturational gradient in the kidney of 24-d rats between the well developed juxtamedullary nephrons and the more newly formed superficial nephrons (17). The results of the present study, therefore, do not rule out that very immature nephrons differ in the energy sources for $\mathrm{Na}$ transport.

It is well documented that the oxygen consumption of the mature kidney is related to the amount of reabsorbed $\mathrm{Na}(5,9,16$, 18). The results of the present study show that this relationship is also true for the immature kidney. The large increase in GFR and the corresponding large amount of reabsorbed $\mathrm{Na}$ that was induced by VE in young rats was followed by a large increase in oxygen consumption.

The 24-d VE rats did, however, have a significantly higher renal $\mathrm{Na} / \mathrm{O}_{2}$ ratio than the rats in the other three groups. By increasing the renal $\mathrm{Na} / \mathrm{O}_{2}$ ratio, the immature kidney was able to conserve some oxygen during VE. This ability of the immature kidney might be explained by two mechanisms: (1) increased passive reabsorption of $\mathrm{Na}$ and/or (2) a change from aerobic to anaerobic energy sources. The proximal tubule of the immature nephron has a relatively high hydraulic conductivity (14) and the transtubular pressure gradients during VE (12) could induce a passive paracellular reabsorption of fluid and $\mathrm{Na}$. In the distal tubule, evidence of a higher proportion of anaerobic energy production compared to that of the proximal tubule is found (20). Immature nephrons reabsorb a higher proportion of filtered $\mathrm{Na}$ in the distal tubule than mature nephrons (3). During VE, this high fractional reabsorption in the immature compared to the mature distal nephrons is even more pronounced (3). The immature kidney shows a higher degree of anaerobic energy sources than the more mature (10). The increase in renal $\mathrm{Na} / \mathrm{O}_{2}$ ratio in response to $\mathrm{VE}$, however, is not necessarily due to ontogenic changes in energy sources. The degree of VE used in the present study (5-6\% of the bw) only increased the GFR and the amount of reabsorbed $\mathrm{Na}$ significantly in the young rats. When adult rats are volume expanded by $10 \%$ of the bw, they have a $20 \%$ increase in the amount of filtered $\mathrm{Na}$ and there is a parallel increase in the renal $\mathrm{Na} / \mathrm{O}_{2}$ ratio (22).

The findings might have several clinical implications. GFR is low in the newborn human infant $(1,7,19)$. GFR increases rapidly in the full term infant and more slowly in the preterm infant during the first wk of life (1). This implies that the renal oxygen demand is low immediately after birth and lower in preterm than in full term infants. It is also of interest that infants with low oxygen uptake due to severe RDS also have a very low GFR (8, 13).

Copyright (C) 1982 International Pediatric Research Foundation, Inc. 0031-3998/82/1605-0351\$02.00/0
A large increase in GFR following VE has also been observed in the human infant (19). This increase in GFR will result in a large increase in renal $\mathrm{Na}$ reabsorption since human infants also have a blunted natriuretic response to VE (2). We therefore suggest that the possibility of an increase in renal oxygen demand should be considered before increasing the fluid and salt intake of newborn infants.

In summary, this study shows that the energy demands of the immature kidney are related to the GFR and the amount of reabsorbed $\mathrm{Na}$. If the GFR and the amount of reabsorbed $\mathrm{Na}$ increase, the oxygen consumption also increases. The amount of increase, however, is less than it would be if the renal $\mathrm{Na} / \mathrm{O}_{2}$ ratio was fixed.

\section{REFERENCES AND NOTES}

1. Aperia, A., Broberger, O., Elinder, G., Herin, P., and Zetterström, R.: Postnatal development of renal function in preterm and fullterm infants. Acta Paediatr. Scand., 70: 183 (1981).

2. Aperia, A., Broberger, O., Thodenius, K., and Zetterström, R.: Renal response to an oral sodium load in newborn fullterm infants. Acta Paediatr. Scand., 61: 670 (1972)

3. Aperia, A. and Elinder, G.: Distal tubular Na reabsorption in the young rat. Evidence for a heterogeneous functional development of the nephron. Am. J. Physiol., 240: F487 (1981).

4. Aperia, A. and Herin, P.: Development of glomenular perfusion rate and nephron filtration rate in rats 17-60 days old. Am. J. Physiol., 228: 1319 (1975).

5. Bálint. P. and Forgács, I.: Sauerstoffverbrauch der Niere in verschiedenen experimentellen Zuständen. Pflügers Arch., 227: 558 (1963).

6. Bankir, L., Trinh Trang Tan, M.-M., and Grüfeld. J.-P.: Measurement of glomerular blood flow in rabbits and rats: erroneous findings with $15 \mu \mathrm{m}$ microspheres. Kidney Int., 15: 126 (1979).

7. Barnett, H. L.: Renal physiology in infants and children. I. Method for estimation of glomerular filtration rate. Proc. Soc. Exp. Biol. Med., 44: 654 (1940).

8. Broberger, U. and Aperia, A.: Renal function in idiopathic respiratory distress syndrome. Acta Paediatr. Scand., 67: 313 (1978).

9. Deetjen, P. and Kramer, K.: Die Abhängigkeit des $\mathrm{O}_{2}$-Verbrauchs der Niere von der Na Rückresorbtion. Arch. Ges. Physiol., 273: 636 (1961).

10. Dicker, S. E. and Shirley, D. G.: Rates of oxygen consumption and of anaerobic glycolysis in renal cortex and medulla of adult and newborn rats and guineapigs. J. Physiol., 212: 235 (1971).

11. Elinder, G.: Renal response to isotonic volume expansion in the developing rat. Acta Physiol. Scand., Suppl. 490 (1980).

12. Elinder, G., Aperia, A., Herin, P., and Källskog, Ö.: Effect of isotonic volume expansion on glomerular filtration rate and renal hemodynamics in the developing rat kidney. Acta Physiol. Scand., 108: 411 (1980).

13. Guignard, J. P., Torrado, A., Mazouni, S. M., and Gautier, E.: Renal function in respiratory distress syndrome. J. Pediatr., 88 : 845 (1976).

14. Horster, $M$. and Larsson, L.: Mechanisms of fluid absorption during proximal tubule development. Kidney Int., 10: 348 (1976).

15. Horster, M. and Valtin, H.: Postnatal development of renal function: micropuncture and clearance studies in the dog. J. Clin. Invest., 50: 779 (1971).

16. Kiil. F.: Blood flow and oxygen utilization by the kidney. In: J. W. Fisher: Kidney Hormones. pp 1-30 (Academic Press, New York. 197I).

17. Larsson, L.: The ultrastructure of the developing proximal tubule in the rat kidney. J. Ultrastruct. Res., 51: 119 (1975).

18. Lassen, N. A., Munch, O., and Thaysen, J. H.: Oxygen consumption and sodium reabsorption in the kidney. Acta Physiol. Scand., S1: 371 (1961).

19. Leake, R. D., Zakauddin, S., Trygstad, C. W., Fu, P., and Oh, W.: The effects of large volume intravenous fluid infusion on neonatal renal function. J. Pediatr., 89: 968 (1976).

20. Weinstein, S. W. and Klose, R. M.: Micropunction studies on energy metabolism and sodium transport in the mammalian nephron. Am. J. Physiol., 217: 498 (1969).

21. Weinstein, S. W. and Szyjewicz, J.: Individual nephron function and renal consumption in the rat. Am. J. Physiol., 277: 171 (1974).

22. Weinstein, S. W. and Szyjewicz, J.: Single-nephron function and renal oxygen consumption during rapid volume expansion. Am. J. Physiol., 231: 1166 (1976).

23. Presented in part at the Fifth International Pediatric Nephrology Symposium in Philadelphia USA, Oct 6-10, 1980, and published in abstract form in Pediatr. Res., 14: 987 (1980).

24. Requests for reprints should be addressed to: Göran E. A. Elinder, M.D., Department of Pediatrics, Karolinska Institute, St. Göran's Children's Hospital, Box 12500 , S-112 81 STOCKHOLM, Sweden.

25. This research was supported by grants from the Swedish Medical Research Council (B80-19X-3644-09C) and grants from the Research Funds of the Karolinska Institute.

26. Received for publication May 8, 1981

27. Accepted for publication November 1, 1981 